ANUARIo de Estudios MEdiEvales 48/2, julio-diciembre de 2018, pp. 723-747

ISSN 0066-5061

https://doi.org/10.3989/aem.2018.48.2.07

\title{
VIEJAS LECTURAS PARA NUEVOS LECTORES. LOS BALADROS CASTELLANOS Y LAS REESCRITURA Y ACTUALIZACIÓN DE LA LITERATURA ARTÚRICA EN EL FINAL DE LA EDAD MEDIA*
}

\author{
OLD READINGS FOR NEW READERS. THE CASTILIAN BALADROS \\ AND THE REWRITING AND UPDATING OF ARTHURIAN LITERATURE \\ DURING THE LATE MIDDLE AGES
}

\author{
SANTIAGO GUTIÉRREZ GARCÍA \\ Universidad de Santiago de Compostela \\ http://orcid.org/0000-0001-6005-9248
}

\begin{abstract}
Resumen: El Baladro del sabio Merlín (editado en 1498 y 1535) constituye uno de los ejemplos más destacados de la recepción de la literatura artúrica en la Península Ibérica durante el final de la Edad Media. El Baladro desciende de la sección central del ciclo de la Post-Vulgata -o Merlin-, compuesto en Francia entre 1230 y 1240, en un contexto cultural e ideológico muy diferente del castellano de los siglos XV y XVI. Por ese motivo, los textos hispánicos fueron sometidos a una serie de modificaciones, que buscaban la adecuación de la obra al horizonte de expectativas de su nuevo público. Esto conllevó la reinterpretación de ciertos pasajes, de acuerdo con la ideología del contexto de recepción y su consiguiente reescritura. El presente trabajo analiza el capítulo en el que se relata la entronización del rey Arturo y cómo estos procedimientos de reescritura conllevaron una reinterpretación de los conceptos sociales y políticos a los que allí se alude.
\end{abstract}

Palabras clave: literatura artúrica; ciclo de la Post-Vulgata; Baladro del sabio Merlín: nobleza; monarquía; sociedad; siglo $\mathrm{XV}^{1}$.

Abstract: The Baladro del sabio Merlín (published in 1498 and 1535) is one of the most important examples of how Arthurian literature was received in the Iberian Peninsula in the later Middle Ages. The Baladro descends from the central section of the Post-Vulgate Cycle -or Merlin-, composed in France between 1230 and 1240, in a cultural and ideological context very different from that existing in Castile in the $14^{\text {th }}$ and $15^{\text {th }}$ centuries. For this reason, the Hispanic texts underwent a series of modifications, in order to adapt the work to the horizon of expectations of the new public. This involved the reinterpretation of some passages, in accordance with the ideology of the context of reception, and its consequent rewriting. The present article analyses the chapter in which King Arthur's enthronement is related and how these rewriting processes involved a reinterpretation of the legal, social and political concepts referred to in it.

Keywords: Arthurian literature; Post-Vulgate cycle; Baladro del sabio Merlín; nobility; monarchy; $15^{\text {th }}$ century ${ }^{1}$.

1 Abreviaturas utilizadas: Baladro 1498 = Hernández, María Isabel (ed.) (1999), El Baladro del sabio Merlín con sus profecías, Gijón, Trea, vol. II; Baladro 1535 = Bonilla San Martín, Adolfo (ed.) (1907), El Baladro del sabio Merlín, en Libros de caballerías. Primera parte: ciclo artúrico, ciclo carolingio, Madrid, Bailly-Baillière, pp. 3-162; Merlin = Micha, Alexandre (ed.) (1979), Robert de Boron. Merlin, roman du XIII siècle, Ginebra, Droz.

\footnotetext{
* El presente trabajo se ha realizado en el marco del proyecto de investigación "El ciclo artúrico de la "Post-Vulgate" puesto en cuestión: la naturaleza del modelo y la relación entre los derivados ibéricos reconsiderados", financiado por el Ministerio de Economía y Competitividad (Ref. FFI2016-78203-P).

Cómo citar este artículo: Gutiérrez García, Santiago (2018), Viejas lecturas para nuevos lectores. Los Baladros castellanos y las reescritura y actualización de la literatura artúrica en el final de la Edad Media, "Anuario de Estudios Medievales" 48/2, pp. 723-747. https://doi.org/10.3989/aem.2018.48.2.07

Copyright: (C) 2018 CSIC. Este es un artículo de acceso abierto distribuido bajo los términos de la licencia de uso y distribución Creative Commons Reconocimiento 4.0 Internacional (CC BY 4.0).
} 
Es aserto admitido que la materia de Bretaña está representada en la España medieval por un número que se ha considerado escaso de testimonios directos $^{2}$, a los que acompaña, es cierto, una cantidad algo mayor de referencias secundarias, las cuales, en todo caso, no alcanzan a equipararse con las que se encuentran en otras zonas de Europa ${ }^{3}$. Por lo que se refiere a Castilla, esta circunstancia no deja de ser algo paradójica, puesto que, a pesar de esa supuesta escasez documental, que ha llegado a relacionarse con una la débil implantación de la materia bretona en la Península, su presencia se constata hasta el final de la Edad Media y aun se prolonga durante los comienzos del siglo XVI. Y lo hace incluso con la energía suficiente como para servir de principal modelo a la eclosión desbordante de los libros de caballerías renacentistas ${ }^{4}$. Igualmente llamativo se presenta el repunte observado en las últimas décadas del siglo XV y las primeras del XVI, cuando se observa un aumento de los testimonios artúricos conservados, en un arco cronológico que comenzaría en 1498, con la publicación del Baladro del sabio Merlín por Juan de Burgos, y que llega a 1535, en que aparecen en Sevilla una nueva versión del Baladro junto a la Demanda del Santo Grial. Aún podría ampliarse dicho período, si se tienen en cuenta los textos que Pedro Ortiz insertó en el volumen hoy depositado en la Biblioteca Universitaria de Salamanca (ms. BUS 1877), que se data ca. 1470, o el fragmentario Tristán de Leonís de la Biblioteca Nacional de Madrid (mss. BNE 20262 y 22644), de realización más incierta a lo largo del siglo XV.

Por su condición de manuscritos, estos últimos ejemplares no ocultan un hecho a tener en cuenta: que la repentina reaparición de la literatura artúrica está en buena medida asociada a la implantación de la imprenta por tierras ibéricas y a la capacidad de aquélla de sumarse a los nuevos métodos de reproducción y difusión libraria. No se trata sólo de que la moda del libro impreso supusiese la desaparición de los viejos códices manuscritos ${ }^{5}$, sino de que la formación de un nuevo mercado editorial, alimentado por el éxito de los primeros relatos caballerescos, principalmente por el Amadís de Gaula

\footnotetext{
${ }^{2}$ Una estimación acerca del número de testimonios artúricos que pudieron circular por la Península, Soriano 2013. Para los testimonios hispánicos conservados, véase Lucía 2015.

${ }^{3}$ Lucía 2013, p. 369, en donde se califica de desolador el panorama que ofrecen los testimonios artúricos ibéricos, por su escasez. El contraste más llamativo se establece con los textos franceses, que sobrepasan los quinientos testimonios, aproximadamente la mitad de los conservados en toda Europa, Middleton 2006.

${ }^{4}$ Con razón se ha calificado a los héroes de las novelas de caballerías renacentistas de nietos de Arturo e hijos de Amadís, Trujillo 2011.

${ }^{5}$ Lucía 2013, p. 383 identifica varios factores que contribuyeron a la desaparición de los manuscritos caballerescos medievales, como la difusión de la imprenta, la eclosión de las novelas de caballerías renacentistas, la demanda de papel en el siglo XVI, los expurgos en bibliotecas o los cambios en los modelos librarios durante el siglo XVI.
} 
(1508) y sus continuaciones, debió de reclamar la edición de más narraciones del mismo género. La primera mitad del siglo XVI contempla la irrupción y el dominio de las novelas de caballerías, con una fase inicial de éxito entre los años 1501 y $1530^{6}$, fechas éstas que, como se acaba de ver, se acercan significativamente a la primera y las últimas impresiones artúricas españolas. Ante la demanda creciente del público lector y las dificultades de los editores para proveerlo de obras originales, habría de recurrirse a la recuperación de viejos relatos medievales ${ }^{7}$, aun a costa de pasar por las prensas textos pertenecientes a otros géneros, como la Corónica del Çid Ruy Díaz, que en 1498 salió del taller sevillano de Tres Compañeros Alemanes ${ }^{8}$. O como el Libro del caballero Zifar, publicado en 1512 por la imprenta sevillana de Jacobo Cromberger, al que incluso formalmente se dotó de las características editoriales adjudicables a los ya reconocibles libros de caballerías; entre ellas, la portada en la que había un grabado con jinete, a la manera del Amadís de Gaula de Montalvo, que había publicado en Zaragoza Jaime Coci (1508) ${ }^{9}$.

Las posibilidades de una obra para incorporarse a este naciente género editorial de los libros de caballerías pasaban por su capacidad para adaptarse a las exigencias del nuevo modelo de lector. Y dicha adaptación imponía una reinterpretación tanto de los componentes temáticos de las obras, como formales de los libros en los que se difundían. Ahora bien, tras este proceso de actualización no deben verse simples maniobras comerciales de los libreros, pues de hecho se inscribe en un marco evolutivo mucho más amplio, inherente al carácter diferido de la comunicación literaria y a la necesidad de colmatar la distancia que siempre existe entre el autor-emisor y el público-receptor ${ }^{10}$. Dicho con otras palabras, la literatura artúrica castellana del siglo XV, basada en modelos que remontaban a textos franceses del siglo XIII, hubo de verse sometida a un constante proceso de adecuación, que posibilitase la recepción y, traducción mediante, la asimilación de dichos textos y su difusión a lo largo de toda la Baja Edad Media. Los relatos artúricos del siglo XV, por tanto, se compusieron dotándolos con mecanismos pensados para que esa distancia temporal e ideológica pudiese ser salvada. Y a menudo, esto implicaba la reescritura de los textos, de manera que dichos cambios articulasen una nueva

\footnotetext{
${ }^{6}$ Green Jr. 1980, p. 353.

${ }^{7}$ Sobre esta pervivencia de las historias de origen medieval en la literatura del siglo XVI llama la atención Infantes 1989, pp. 118-120.

${ }^{8}$ Editada por Baranda 1995. En 1512, Fadrique de Basilea publicó en Burgos una versión extendida, conocida como Crónica particular del Cid.

${ }^{9}$ Sobre el género literario al que adscribir esta versión impresa del Caballero Zifar, véase Cacho 1999.

${ }^{10}$ La base teórica para estas reflexiones acerca de la recepción literaria y el concepto de horizonte de expectativas procede de Jauss 1976, p. 171; 1978, p. 113.
} 
lectura de los mismos. Lo interesante de tales modificaciones estriba en que en no pocas ocasiones se centran en pasajes que contienen conceptos claves desde el punto de vista de la comprensión de la obra o de la ideología de la época, de ahí que su análisis descubra aquellos elementos en los que se hubo de producir un reajuste en el horizonte de expectativas ${ }^{11}$ de los lectores del siglo XV.

Un ejemplo de lo que acabamos de exponer lo constituye el Baladro del sabio Merlín ${ }^{12}$, cuyas dos ediciones impresas conservadas, la de Burgos de 1498 y la de Sevilla de 1535, remitían en última instancia a la sección central de la Post-Vulgata artúrica. Ésta, a su vez, estaba compuesta por el Merlin en prosa, atribuido a Robert de Boron, y la Suite du Merlin y habría sido redactada, como el ciclo en el que se integraba, entre los años 1230 y 1240. La distancia cronológica y cultural de los testimonios castellanos y los textos franceses de origen hacen pensar que parte de las modificaciones textuales que frente a su modelo muestran los Baladros se deberían, además de a las vicisitudes de una transmisión incierta y azarosa ${ }^{13}$, a dicha exigencia de actualización ideológica. $\mathrm{Y}$, aunque las muestras de reescritura se encuentren dispersas a lo largo del relato, resultan especialmente interesantes aquellos ejemplos que se concentran en los episodios en los que se describe el traspaso de poder de Úter Padragón a Arturo. Esto se debe a que en esa sección de la obra se aducen diversos conceptos legales que propician la reflexión sobre las instituciones y las estructuras jurídicas del reino. La alusión a éstas obliga a un posicionamiento respecto a las concepciones políticas y legales del texto de origen, que o bien son asumidas en su integridad, o bien se someten a las pertinentes modificaciones. Esto último relevaría una discrepancia entre las instituciones que propone el texto de origen, por un lado, y, por otro, la realidad sociopolítica del siglo $\mathrm{XV}$, en la que se lleva a cabo el proceso de recepción literaria. El reelaborador, en tal coyuntura, estaría descubriendo parte de las expectativas asumibles por los lectores, a los que se dirigía, así como aquellos pormenores que éstos considerarían extraños o no aceptables. Es lo que se muestra, por ejemplo, con ocasión de la elección del nuevo rey de Bretaña por medio de la espada clavada en la roca. Antes de que empiece dicha prueba, el arzobispo de Londres, encargado de regularla, alecciona al pueblo allí congregado acerca de los designios de Dios para con el reino. En el Baladro de Burgos lo hace en estos términos:

${ }^{11}$ Sobre este concepto y la recepción de los textos medievales, véase Bäuml 1980, p. 253, quien lo inserta en la dialéctica oralidad-escrituralidad de la literatura medieval.

${ }^{12}$ A lo largo del trabajo nos referiremos a esta obra como Baladro del sabio Merlín, en singular, o como Baladros, en plural. Este segundo caso lo emplearemos cuando convenga resaltar la idea de que existen dos redacciones de esta obra, cada una de ellas dotada de características particulares.

${ }^{13}$ Estudiada, entre otros, por Gracia 2007 y 2012, a cuya bibliografía enviamos para una consideración más pormenorizada de esta cuestión. 
Fermosa elección nos enbió Dios, ca Él quiso que justicia terrenal fuese por espada. E dio a cavallero en escomienço de las tres órdenes para la santa Eglesia guardar e agora quiso que por espada fuese nuestra elección; e bendito sea el su nombre. E Él bien sabe a quién ha de dar esta justicia. E non se acucien los altos ombres, ca el Señor no quiere que por riquezas ni por orgullo sea la espada tirada. Otrosí, non se ensañen los pobres contra los ricos, que Dios no sepa quál es el mejor ${ }^{14}$.

Respecto a este, el texto de Sevilla muestra algunas variantes significativas:

Fermosa elecion nos enbio Dios, ca el quiso que justicia terrenal fuesse por espada; e dio a cada cauallero en esto comienço de las tres ordenes para yglesia guardar, e agora quiso que por espada fuese nuestra elecion; e bendito sea el su nonbre, que el bien sabe a quien ha de dar esta justicia, e no se cuyten los altos honbres, ca el Señor no quiere que por riqueza ni por orgullo sea la espada tirada, e otrosi no se ensañen los pobres si los ricos primero tirasen o prouasen, ca no ay tal de vos que Dios no sepa qual es el mejor ${ }^{15}$.

Esta segunda versión estaría más cercana a la que reproducen las redacciones francesas:

l'arcevesquez... lor mostre les beles miracles que Nostre Sires avoit por els faites et lor dist que veire election avoit et que Nostre Sires, quant il comenda justice terrienne, si la mist en glaive d'espee; et la jostise qui seur la laie gent doit estre d'ome lai, si est par espee; et l'espee fu baillee, au comencement des .III. ordres, au chevalier por desfandre Sainte Eglise et jostise a tenir, "et Nostre Sire or nos refait par espee la nostre election, et sachiez bien tuit que il a bien porveu et esgardé cui il viaut baillier ceste jostise et ne se hastent ja li riche home de l'essaier, qu'ele ne vaut mie par richesce ne par orgoil; ne ne se corrocent mie li povre, se li riche essaient avant, que il est droiz et raisons que cil que l'en cuide et tient as plus hauz homes au monde doivent bien essaier avant, qu'il n'a nul de vos qui saiges soit qui ne deust faire a son esciant roi et seignor dou plus prodome"16.

${ }^{14}$ Baladro 1498, cap. XVII, p. 63.

${ }^{15}$ Baladro 1535, cap. CXXVIII, p. 48.

${ }^{16}$ Merlin, cap. 84, pp. 271-272. De acuerdo con el aparato de variantes que ofrece Micha, sólo el ms. BNF 24394 ( $A^{\prime}$ ') y el ms. 526 de la Biblioteca Universitaria de Bonn (B') presentan una lectura significativa divergente en la parte final de este pasaje: "essaier avant, car il n'i a nesun se il le savoit qu'il ne deust eslire le plus preudomé de nos tos a faire roi”. 
Como se observa, y más allá de cierta confusión al inicio del pasaje de ambos Baladros, acaso debida a la referencia a los tres órdenes sociales, no del todo comprendida por los reelaboradores hispanos, la redacción del incunable burgalés diverge hacia el final del texto introduciendo una variante digna de mención respecto al modelo francés y a la edición sevillana. En el ejemplar de 1498 se omite la referencia al orden de probatura de la espada y al derecho que, aunque en último lugar, asistía al pueblo menudo para intentar la prueba. En este caso no se trata de que el pueblo se vea relegado a la hora de intentar la extracción de la espada, que era lo que según el Merlin y la edición de Sevilla podía ocasionar un posible enojo por parte de las clases populares, sino de que en el incunable de 1498 estas últimas quedan excluidas del rito de probatura, cerrándosele, entonces, a sus miembros el acceso a la dignidad regia. Con este giro, Burgos, es cierto, desplaza el argumento de la no participación popular hacia la condición igualatoria que contiene la elección por Dios de un rey, no según las riquezas y el linaje, sino de acuerdo con las virtudes personales. Pero lo hace teniendo presente que, si la prueba se limita a los nobles, tales virtudes estarán albergadas, necesariamente, en un representante de este estamento.

El desvío que en dicho pasaje introduce el Baladro burgalés vendría de esta forma a compensar una insistencia, que se consideraría excesiva, en la virtud individual como criterio exigible para acceder al trono, eco de las tesis bartolistas sobre la nobleza, que ponían en cuestión la existencia de una aristocracia de linaje y que en el siglo XV constituían uno de los núcleos temáticos del debate sobre la esencia y la razón de ser de la nobleza y de la caballería ${ }^{17}$. De hecho, un poco antes, el mismo arzobispo de Londres había sido explícito al respecto, advirtiendo de que para la elección del nuevo soberano riqueza ni fidalguía non ha menester, sino la voluntad de Dios ${ }^{18}$. Declaraciones de este tipo, como es obvio, se anticipan a la entronización de Arturo, por aquel entonces un niño de ascendencia desconocida y condición humilde. No en vano, previenen contra el argumento previsible que los nobles del reino oponen cuando Arturo extrae la espada y adquiere los derechos al trono:

E los ricosombres dixeron: No queremos nos contradezir a Dios, mas avemos esto a grand maravilla, de niño de tan poco estado e de tan baxo linaje, ser señor de nos... nos non sabemos cosa de su fazienda ${ }^{19}$.

\footnotetext{
${ }^{17}$ Heusch 2000, pp. 11-23; Rodríguez Velasco 1996, pp. 283-304.

${ }^{18}$ Baladro 1498, cap. XVII, p. 62; "riqueza ni hidalguia no es menester, sino la voluntad de Dios" (Baladro, 1535, cap. CXXVIII, p. 48). Véase asimismo Merlin, cap. 84, p. 270: "richesce ne hautesce ne fiertez n'i a mestier, se la volanté non dou voir seignor dou ciel".

${ }^{19}$ Baladro 1498, cap. XVII, p. 65; "e los ricos honbres dixeron: No queremos nos a Jesu Christo desto contradezir, mas auemos a marauilla de tan niño, honbre de tan baxo linage, ser
} 
La reacción de los nobles, aun siendo esperable, delata la inquietud que sacudía a la aristocracia tardomedieval ante el acceso masivo a la nobleza por parte de las capas sociales inferiores. Frente a la idea de un estamento encastillado en sus privilegios y de la cerrazón de las vías de acceso a las prebendas que proporcionaban la nobleza y la caballería, la Baja Edad Media se caracterizó, al menos en Castilla, por la diversidad y relativa facilidad con que se accedía a dicho estatuto supuestamente exclusivo. Aunque se trataba de una tendencia que se rastrea en siglos anteriores, el escándalo que tal situación planteaba en el siglo XV provocó continuos apremios al rey por parte de la aristocracia, para que pusiese remedio a esa situación. A pesar de lo cual, los propios monarcas no dejaron de explotar su potestad de ennoblecer por los servicios que se les prestaba, que tanto podían ser bélicos, como burocráticos o académicos, todo ello como expresión de sus aspiraciones absolutistas y como medio de ejercer su generosidad en el desempeño del poder con la adhesión de nuevos partidarios y soportes de la monarquía, pero también como recurso inmediato para conseguir dinero ${ }^{20}$. La ansiedad de clase que provocaba esta hemorragia de títulos y honores explica los reparos de los nobles del Baladro ante la elección de Arturo. Pero en este caso, además, podría considerarse que una actitud semejante, defensiva y conservadora, estaría siendo asumida por el reelaborador de la obra, de ahí la reescritura que lleva a cabo al describir el mecanismo de elección real, en cuya carga excluyente profundiza. Con ésta se cerraría el paso a los villanos, a los que Arturo pertenece sólo en apariencia.

Pero el conflicto entre virtud y sangre y la conciencia de exclusivismo estamental se plantea de nuevo cuando Antor revela la verdadera ascendencia de Arturo y da a conocer el sacrificio realizado por su familia durante su crianza. Este consiste, significativamente, en haber privado a su hijo legítimo de mamar de la leche de su madre en favor de Arturo, dándole a tomar del pecho de una villana. Por eso, el aviso de Antor al nuevo rey: por vos es desnaturado de todo derecho de ombre fidalgo, por la natura de la leche de una villana,

rey e señor de nos... nos no sabemos cosa de su fazienda" (Baladro, 1535, cap. CXXXIII, p. 50). Véase asimismo Merlin, cap. 89, p. 283: "Lors dient li baron: Biau sire, nos ne poons pas estre ne ne devons contre la volanté Nostre Seingnor, mais ce nos est molt grant merveille de si jone home et de si bas afaire qui einsis sera sires de nos... nos [cel enfant] ne l'avons ne veu ne coneu, ne ne savons gaires de son aistre". Declaraciones semejantes se repiten a lo largo de ese capítulo: "parécenos muy estraña cosa un rapaz ser señor de todos nosotros" (Baladro 1498, cap. XVII, p. 64); "parecenos mucho estraña cosa, vn rapaz ser señor de todos nosotros" (Baladro 1535, cap. CXXXII, p. 49). Véase asimismo Merlin, cap. 89, p. 283: "mais ce nos est molt grant merveille de si jone home et de si bas afaire qui einsis sera sires de nos".

${ }^{20}$ Véase, por ejemplo, Gerbet 1972, en donde se analizan los conflictos bélicos tardomedievales como una de las posibles vías de entrada masiva a la nobleza. La autora llega a referirse a "une véritable braderie de l'annoblissement" (p. 295) por parte de los monarcas, deseosos de reclutar partidarios. 
que por criar a vos ge lo dimos ${ }^{21}$. Este pasaje se encuentra tanto en la versión de 1498 como en la de 1535, mientras que el texto francés no mencionaba la pérdida de la condición hidalga, sino sólo una desnaturalización que afectaba al carácter y la condición moral de Keu: et se il est fols et vilains et fel, voz le devez bien soufrir, que ces mauvaises tesches a il aues por vos et prises en la garce que il alaita, et por voz nourrir est il desnature $z^{22}$.

La discrepancia entre la lectura que contienen los Baladros castellanos interesan a un concepto clave en la reconfiguración social de la Baja Edad Media castellana, el de naturalidad, pues constituía uno de los pilares sobre los que la monarquía buscaba la legitimación a su poder absoluto. Aunque dicho concepto se encuentra en textos del siglo XII, fueron precisamente las obras legislativas alfonsíes las que se preocuparon en definirlo con precisión y ahondar en sus implicaciones políticas. La naturalidad definía un tipo de relación basada en la pertenencia del individuo a una comunidad, de acuerdo con hasta diez modos de relación reducibles a dos grupos: por lazos personales establecidos entre dos personas o por adscripción a un territorio ${ }^{23}$. El sentido de estas relaciones, vertical -basado en la desigualdad de los implicados y afectada por la idea de señorío- u horizontal -entre iguales- fijaba una serie de obligaciones, derechos o solidaridades, que asentaban la pertenencia con mayor vigor del que poseían los vínculos vasalláticos. En especial, a medida que la naturalidad fue potenciando, con el paso del tiempo, su sentido territorial, en detrimento de los lazos personales ${ }^{24}$.

La vigencia del concepto de naturalidad y su derivación hacia la doctrina del señorío natural mostraba toda su vigencia en la Castilla del siglo XV debido, no sólo, como se acaba de insinuar, a su utilización por parte del poder regio en expansión, sino porque determinaba la pertenencia o exclusión a los círculos de solidaridad social que sustentaban la sociedad de bajomedieval. En

${ }^{21}$ Baladro 1498, cap. XVII, p. 64; "por vos es desnaturado de todo derecho de hombre fidalgo, por la natura de la leche, que vos mamastes de su madre y el mamo leche de vna villana" (Baladro 1535, cap. CXXX, p. 49).

22 "Et se il est fols et vilains et fel, voz le devez bien soufrir, que ces mauvaises tesches a il aues por vos et prises en la garce que il alaita, et por voz nourrir est il desnaturez" (Merlin, cap. 87, p. 278).

${ }^{23}$ Alfonso X, en Las Siete Partidas, ed. Real Academia de la Historia, la Cuarta Partida, desglosa esas diez maneras de relación: "la primera et la mejor es la que han los homes con su señor natural, porque tambien ellos como aquellos de cuyo linage decenden, nascieron, et fueron raigados et son en la tierra onde es el señor; la segunda es la que viene por razon de vasallage; la tercera por crianza; la quarta por caballeria; la quinta por casamiento; la sexta por heredamiento; la setena por sacarlo de cativo ó por librarlo de muerte ó deshonra; la ochava por aforramiento de que non rescibe prescio el que lo aforra; la novena por tornarlo cristiano; la decena por moranza de diez años que faga en la tierra maguer sea natural de otra" (Partida IV, título XXIV, ley II, t. II, p. 131).

${ }^{24}$ Véase, sobre este particular, Martin 2008. 
especial, por sus repercusiones sobre los límites de la nobleza, tan debatidos. En efecto, si el origen y la naturaleza del poder regio habían sido motivo de polémica y reflexión durante las centurias finales de la Edad Media, también fue cuestionada la esencia de en qué consistía ser noble. Una corriente interpretativa sostenía un concepto natural de nobleza, surgida con la Creación misma y que se comunicaba por medio de la sangre. Dicha concepción sobrepujaba la idea de linaje, puesto que valoraba la idea de transmisión en el seno de una familia, a la vez que defendía una idea cerrada del ser nobiliario, impermeable a la entrada de nuevos miembros por la vía del servicio y las mercedes regias. Como consecuencia, los defensores de esta doctrina hacían del tiempo un factor de ennoblecimiento, lo que situaba a la nobleza vieja por encima de la nueva ${ }^{25}$. La aristocracia nobiliaria se situaba así por encima de las prerrogativas de que al respecto gozase la monarquía, puesto que, al remontar sus privilegios al origen del mundo, podían defender que éstos les habían sido otorgados, no por un rey, sino por Dios mismo ${ }^{26}$.

Pero además, la idea de nobleza natural conllevaba un segundo debate, ya que, aceptada ésta, quedaba sin resolver la cuestión de si sólo la sangre convertía a alguien en noble, con independencia de las virtudes o vicios que lo adornasen. Es decir, si la recepción de la nobleza era absolutamente pasiva, a través de la herencia, o si implicaba un aspecto activo, a través de la adquisición. Y, de manera inversa, si podía perderse en caso de una conducta indigna. Aunque las opiniones al respecto oscilaban entre concebir la nobleza por encima de tales contingencias y considerar que se perdía en caso de degeneración moral, la postura de compromiso consistió en identificar virtud y sangre, siendo ambas entre sí consecuencia y causa; o lo que es lo mismo, complementarias y necesarias ${ }^{27}$. Sin embargo, el mantenimiento de las virtudes inherentes a la dignidad de la sangre conllevaba una serie de comportamientos que el noble asumía de manera instintiva, como constituyentes de su forma de ser. Por ejemplo, en lo referido a las comidas, entre las cuales se inclinaría por

\footnotetext{
${ }^{25}$ Véanse, por ejemplo, los siguientes pasajes del Nobiliario vero de Ferrán Mexía: "De do se conprehende quel nuevo noble non puede ser noble de sy mismo por que non trae linage de los pasados" (González-Vázquez 2013, libro II, conclusión III, cap. I, p. 312); "en la antigüedad del linage está o yaze la nobleza, o al menos allende de la quarta generaçión" (ibidem, libro II, conclusión III, cap. XXVIII, p. 345); "aquel que desçiende de alto e antigo linaje solamente es noble" (ibidem, libro II, conclusión III, cap. XXVIII, p. 346) "se prueva ser más noble e mayor nobleza la antigua nobleza del antiguo noble que aquella de aquel, el qual es criado nuevamente noble" (ibidem).

${ }^{26}$ Quintanilla 2008,p. 156. Véase, por ejemplo, la propuesta de Ferrán Mexía (ibidem, libro I, introducción, p. 227). Mexía sostiene que el hombre tiende de forma natural al bien y a la nobleza, de forma que, quien no posee ésta, es porque ha sido corrompido por el pecado (ibidem, libro I, cap. LIII, p. 247).

${ }^{27}$ Véase para estas cuestiones, Quintanilla 2008,pp. 151-158.
} 
alimentos refinados, que purificasen su sangre. Las doctrinas medievales sobre la nutrición no sólo habían elaborado una clasificación de alimentos adecuados a cada estamento social, sino establecían que éstos eran capaces de determinar a las personas. Así, el villano, además de sentirse atraído por productos pesados y groseros, conformaba su carácter de acuerdo con las propiedades que dicha dieta le transmitía. Al respecto, Ferrán Mexía explica que

el nuevo noble es criado gruesamente e la grosedad de su nutritiva han fecho su materia gruesa por respecto de los manjares gruesos, que engendrarán gruesos humores como paresçe en todo aquel que es de obscuro linaje... e la tal gruesa materia trae e engendra gruesas las virtudes del ánima e del entendimiento (...) Pues como el que desçendido de alto, e claro, e antigo linage sea nudrido e criado, por el contrario e en otra ordenada o arreglada observançia, açerca de moderada abstinençia o temprança, asy mismo de delicados, sotiles e digibles manjares, trae natural, e aun hereditariamente más sotiles humores, lo qual es cabsa de asotalizar el yngenio, e levar el entendimiento, e a purificar e a generar más limpia e más pura sangre ${ }^{28}$.

Montanari ${ }^{29}$ observa cómo estas teorías se encontraban ya en la medicina grecolatina y cómo fueron heredadas por la cultura medieval, sólo que ésta añadió un componente social donde la terapéutica clásica se interesaba por cómo los alimentos debían adecuarse a los humores y la complexión individual. El paralelo entre jerarquía social y jerarquía alimentaria se convirtió, a partir del siglo XIV -es decir, la época que nos ocupa- en un medio, otro más, por parte de la aristocracia para defender sus privilegios ante los peligros que encontraba en la movilidad social contemporánea. El desarrollo de teorías alimentarias, que vedaban ciertos alimentos a los villanos, buscaba hurtar el acceso de éstos al poder, tal y como demuestra el interés que al respecto mostraban los tratados contemporáneos sobre la nobleza, al modo del Nobiliario vero. Y, por esto mismo, concluye este estudioso italiano, se otorgaba especial

${ }^{28}$ Ferrán Mexía, Nobiliario vero, libro II, conclusión III, cap. XXVIII, en González-Vázquez 2013, p. 345. Todavía en 1629, Mártir Rizo se hacía eco de esa asociación entre alimentos y clase social en su Historia de Cuenca: "el que deciende de antiguo, y claro linage està alimentado de otra forma con diferente regla, y orden, con moderada abstinencia, ò templança, con delicados, y sutiles manjares, y por esto trae natural, y hereditariamente mas sutiles humores, lo qual es causa de sutilizar el ingenio, eleuar el entendimiento, purificar, y engendrar mas limpia sangre, y mas pura, de lo qual resulta mayor perfeccion en la gallardía de su condicion, en sus virtudes, y costumbres", (Mártir 2008, p. 208), mientras que el ser rústico, que Rizo extiende a la diferencia entre el noble de linaje antiguo y el de linaje nuevo, se debe a que "la grossedad de su nutrimento ha hecho su materia gruessa, respeto de los manjares gruessos, que engendran semejantes humores" (ibidem).

${ }^{29}$ Montanari 1993, pp. 85-94. 
importancia a la nutrición de los niños e, incluso, de los nonatos, pues de ella dependía la condición personal de los futuros caballeros.

Saltan a la vista, entonces, las consecuencias que una alimentación inadecuada podían tener sobre un noble, pues alteraban su constitución humoral y, con ella, su carácter, pero también su condición virtuosa. Tal es lo que le ocurre a Keu, cuyo temperamento queda condicionado de por vida, al haber tomado la leche de una villana y cuya alimentación lo habría desnaturalizado de la nobleza. Asimismo, su apartamiento del ámbito aristocrático se produciría, por otro lado, desde el punto de vista de las relaciones personales y de la vinculación de lealtad que habría establecido con la villana que lo había amamantado. Sobre este particular, resultan significativas algunas de las disposiciones que las Partidas fijaban acerca de las obligaciones que un hombre contraía con aquellos de quienes era natural. Entre las relaciones verticales que establecía la naturalidad el código alfonsí enumera las que una persona establece con Dios, en tanto que Creador y con sus progenitores. Y, al hilo de este segundo supuesto, en el que está involucrada la noción de linaje, se especifica lo siguiente:

Otrosi ha grant debdo con la madre, porque hobo parte en facerle, et levó grant trabajo mientre lo troxo, et grant peligro en parirlo et gran afán en criallo: et aun con el ama que lo crió ha grant debdo, porque le dió su leche en el tiempo que habie meester él nodrescer, et le es asi como madre: et con el amo ha debdo, porque lo crió et lo gobernó en el tiempo que le era meester, et le fue como padre ${ }^{30}$.

El vínculo paterno-filial con el amo corresponde a la deuda que Arturo contrae con Antor, como así lo reconoce el futuro monarca bretón. Mas en este caso no se plantean problemas, gracias a la condición noble de aquél, al que el narrador había descrito como un ombre bueno e es el mejor e más leal de todo el reino en bondad... e el hombre bueno es rico o al definirlo, poco después como caballero ${ }^{31}$. Y la esposa de Antor, por tanto, asumiría un papel

\footnotetext{
${ }^{30}$ Alfonso X, Las Siete Partidas, ed. Real Academia de la Historia, Partida IV, ley XXIV, título 3, t. II, p. 131.

${ }^{31}$ Baladro 1498, cap. XVI, p. 59 y cap. XVII, p. 62. El texto de Sevilla rebaja la condición económica de Antor: "vn honbre bueno... y el es el mejor del reyno de bondad... y el honbre bueno no es rico" (Baladro 1535, cap. CXXI, p. 45). Las versiones francesas, aun con variantes, sugieren el humilde estado de Antor. El texto base de la edición de Micha, que se apoya en los mss. 747 de la Bibliothèque Nationale Française y Add. 32125 del British Museum de Londres, ofrece esta redacción: "un des plus prodomes et des plus leaus de vostre regne... et se n'est mie... trop riches hom" (Merlin, cap. 73, p. 248). Por su parte, los mss. A' (BNF 24394) y $B$ ' (Universitätsbibliothek de Bonn 526), dan esta lección divergente en el trecho final: "et n'est mie bers en rices hom" (ibidem). Véase asimismo Baladro 1535, cap. CXXVII, p. 47. Con ello se acentuaba la deuda de Antor respecto a Úter, por vía de la merced regia, que retribuía el servicio prestado por Antor. El Baladro burgalés, en cambio, elimina este pormenor, que
} 
equiparable al de la madre de Arturo, en tanto en cuanto actuó como ama de cría. El conflicto surge, en cambio, en el caso de Keu, ya que, por haber sido alimentado con la leche de una villana, debía asumir el deudo derivado del señorío natural para con ésta; con lo que, de hecho, quedaba sometido a una no noble y, por consiguiente, él mismo excluido de la élite nobiliaria. De ahí la consternación con que Antor ruega a Arturo merced para su hijo. El refundidor hispano, con sus modificaciones textuales, agranda el drama que vive Antor, quien ve cómo su hijo, no sólo se degrada moralmente, sino que de hecho corre el riesgo de ser apartado de la aristocracia.

Es por todo esto que Antor consideraría que el abajamiento que había sufrido su hijo como una auténtica desnaturalización, una expulsión del estamento al que pertenecía por linaje. La única solución que se le plantea consiste en reclamar el reingreso de Keu en la nobleza, sólo que ahora por vía del servicio a la monarquía y de la merced regia. Tal es lo que le plantea al nuevo soberano, solicitándole para su hijo la merced del oficio de la mayordomía, uno de los puestos de confianza en la casa del rey. Pero, como se acaba de ver, la admisión a la nobleza a través de esta vía era considerada en el siglo XV como de menor valía, frente a la del linaje y a la de la transmisión por la sangre. La escena en que Antor, solicita el cargo para Keu, por eso, reforzaría ante los lectores tardomedievales la imagen del poder regio ostentado por Arturo, al presentarlo en el ejercicio de otorgar mercedes y ennoblecer a miembros de su corte, pero asimismo en el de nombrar a los oficiales de la casa real, que se consideraba una prerrogativa regia, basada en la discrecionalidad absoluta del monarca, en tanto que soberano ex legibus solutus ${ }^{32}$. Al mismo tiempo, al hacer hincapié Antor en el componente sacrificial de su gesto, por haber relegado a Keu a la lactancia de una villana, también mostraría la ansiedad de la nobleza de la época por la salvaguardia de su estatuto privilegiado, identificado éste con la idea de linaje, frente al ascenso de los nobles nuevos. Del mismo modo que páginas antes, como veíamos al tratar la prueba de la espada, el Baladro había mostrado los mecanismos de exclusión y cierre de que disponía la nobleza bretona para asegurarse de que la corona del reino recayese en un aristócrata.

cuestionaría no sólo el estatuto social de Antor, sino el de quien, como Arturo, queda vinculado a él a través de la naturalidad. El incunable intentaría de nuevo el reforzamiento de la figura de Arturo, en tanto que monarca, apartándolo de toda relación con un proceso de ascenso social, como el que en caso contrario protagonizaría Antor. El de Arturo será un ejemplo, no ascenso en la escala social, sino de reconocimiento y recuperación del señorío que le corresponde.

${ }^{32}$ Torres 1982, pp. 53-70, en donde se explica cómo el de mayordomo era un cargo adscrito a la casa del rey, con la categoría de oficial y carente de jurisdicción. García 1993, pp. 229-230, por su parte, advierte de que en Castilla la mayordomía se encuadraba entre los oficios mayores de la casa del rey y estuvo ocupada por grandes nobles. Se trataba, por tanto, de un oficio en el que se cumplía la regla de a mayor cercanía al rey, más promoción social (ibídem, p. 226). 
Pero además, en la edición burgalesa las peticiones que Antor le dirige a Arturo -el cargo de mayordomo para Keu y que éste quede a salvo de la saña regia- añaden un recordatorio según el cual las obligaciones contraídas por el monarca tienen origen por lo que la virtud de la grandeza os obliga ${ }^{33}$. Esta apelación a las virtudes del rey apunta a una identificación entre virtud y linaje, una vía intermedia entre la defensa de la nobleza de sangre y las doctrinas bartolistas, en la que el linaje se salva en la medida en que en él, y sólo en él, anida la virtud. De este modo, sólo los nobles serían virtuosos ${ }^{34}$. Esta tesis, que se encuentra en no pocos tratados sobre nobleza y caballería ${ }^{35}$, será la que adopten mayoritariamente los relatos caballerescos medievales y las novelas de caballerías renacentistas, dando lugar al motivo del personaje en apariencia humilde, cuya sangre suscita en él el deseo innato de cosas nobles, como el ingreso en la caballería, y que termina descubriendo su estirpe aristocrática. El propio Baladro muestra un ejemplo de este motivo en la persona de Tor, criado por Ares el Villano, que, con ocasión de la boda de Arturo y Ginebra, es armado caballero, junto con Galván ${ }^{36}$.

El despliegue de virtudes como esencia, no ya de la nobleza, sino de la misma condición real entronca con las exigencias de moralización que desde el siglo XIII se habían proyectado sobre la institución monárquica. El origen divino de la potestad regia y la mayor amplitud del poder que reclamaba el rey, con aspiraciones a un ejercicio absoluto de tal prerrogativa, descansaban por igual en un freno a su ejercicio incorrecto o desmedido. Si el monarca se consideraba vicario de Dios en la tierra, debía adecuar su conducta al modelo de las virtudes cristianas y orientar su acción de gobierno a la búsqueda del bien común como vía que garantizase la salvación colectiva de su pueblo $^{37}$. La proliferación de specula principis en los últimos siglos de la Edad Media daba respuesta a ese requerimiento de un monarca virtuoso, que se hiciese merecedor del don otorgado por Dios, no sólo por la pertenencia a un

${ }^{33}$ Baladro 1498, cap. XVII, p. 64.

${ }^{34}$ Quintanilla 2008.

${ }^{35}$ Véase, por ejemplo, el testimonio de Gonzalo Fernández de Oviedo en las Batallas y quinquagenas, en donde dicha identificación entre linaje y virtud se realiza por medio de la tesis de que el origen de la nobleza residió en la necesidad de separar a los virtuosos de los ruines: "Así que la masa e origen de todos los ombres una mesma cosa es; pero las virtudes e obras de los mismos ombres an echo diferenciar y apartar los linages y idalguia de los buenos (...) aventajándose con los oscuros" (Pérez de Tudela 1983-2002, vol. II, batalla I, quinquagena III, diálogo ix, p. 211).

${ }^{36}$ Baladro 1498, cap. XXIX, pp. 124-125; Baladro 1535, cap. CCCV, p. 124, cap. CCCVI, p. 125.

${ }^{37}$ Véanse, entre otros, González 2008, pp. 29-30; Haro 1996, especialmente pp. 21, 26 y 52; Leroy 2011, pp. 231-232; Nieto 1988, pp. 55-60; 1997, pp. 61-74; Scandellari 2007, pp. 159-160. 
linaje elegido, sino por el ejercicio del bien aplicado a la acción política con implicaciones morales, mas también espirituales. Pero a la vez, en la demanda del comportamiento virtuoso de los reyes influyó la difusión de las tesis jurídicas romanistas, que incluían la traducción castellana de la Ética a Nicómaco ${ }^{38}$ y que contemplaba como conceptos centrales la idea de reino y, por lo que se refiere a la acción de gobierno, la búsqueda del bien común a través del ejercicio virtuoso del gobierno. No por casualidad, la evolución del género de los specula fue acompañada de propuestas cada vez más explícitas a favor de una consolidación del poder regio, apoyada en la construcción de un modelo político a partir del Derecho Romano ${ }^{39}$. En Castilla este cambio está ligado a la sistematización jurídica de Alfonso X, en la segunda mitad del siglo XIII, pero influye en no pocos de los specula compuestos en los siglos siguientes, entre ellos, por citar un ejemplo destacado, los Castigos e documentos de Sancho IV ${ }^{40}$.

Cobran así sentido las pruebas a que los nobles de Logres someten a Arturo, tras haber extraído la espada y como paso previo a su entronización. Pues, por encima de una intervención divina en la elección del nuevo rey, que esos mismos nobles contemplaban con cierto escepticismo, y frente a la tutela de la Iglesia, encarnada en la figura del arzobispo de Londres, la nobleza del reino impone sus propios criterios de aclamación, los cuales se basan en la citada identificación entre sangre y virtud. A Arturo se le exige que demuestre la primera exhibiendo la segunda, de ahí el interinato que transcurre entre que extrae la espada y se procede a su elección, en la fiesta de la Candelaria, y su unción y coronación, en Pentecostés, durante el cual adopta sus primeras decisiones del gobierno. En esa tesitura, el arzobispo de Londres le ofrece la posibilidad de que escoja sus privados y consejeros y de que reparta tierras y oficios. Sin embargo Arturo actúa con sabiduría: delega en el arzobispo la elección de los cargos de más confianza y pospone las otras decisiones hasta el momento de su coronación. Los nobles comprueban de esta forma cómo sus acciones se adecuan a la moral cristiana y están guiadas por la idea de bien común, pues, como el mismo Arturo declara, están puestas al servicio de Dios e a su volun-

${ }^{38}$ Traducida por Hermann el Alemán a partir del comentario de Averroes (Rodríguez 2003, pp. 145-148). De su vigencia en los años en que se refunden los Baladros véanse, por ejemplo, Heusch 1996; Pagden 1975; Russell, Pagden 1974.

${ }^{39}$ Para la importancia de las Partidas alfonsíes en la difusión de las teorías romanistas por Castilla, véase Nieto 2008.

${ }^{40}$ Véase Bizzarri 1995, pp. 46-56, así como Haro 1996, pp. 49-53, en donde se destaca la promoción que llevan a cabo los Castigos e documentos de Sancho IV de la monarquía absoluta, ligada a conceptos como el del origen divino del poder regio. 
tad e a pro del pueblo ${ }^{41}$. Y llegada la Pascua, en que habría de ser coronado, los nobles lo prueban nuevamente, esta vez, [de] vuestra voluntad, sin consejo que tomés ${ }^{42}$, es decir demostrando por sí mismo qué virtudes posee.

Con todos estos tanteos los aristócratas pretenden comprobar si Arturo posee la sabiduría natural necesaria para ejercer como rey. Y esto, no sólo, como acabamos de apuntar, para que así se revele si Arturo procede de linaje elevado, sino porque ese saber natural se consideraba una virtud gubernativa, necesaria para el oficio de rey. Bajo una consideración dual del conocimiento -adquirido por medio del aprendizaje o poseído de manera innata-, de la que se hacía eco San Agustín y que más tarde reformuló Santo Tomás, los tratados doctrinales del siglo XV distinguirán entre la ciencia, que se aprende, y el seso, que era un don natural ${ }^{43}$. Este último solía encontrarse en los monarcas, puesto que eran personas destinadas por Dios desde su nacimiento a regir a los pueblos; luego su presencia era prueba imprescindible para aceptar a Arturo como soberano, por encima de su apariencia humilde.

La invocación a Dios, que el futuro rey desliza a la hora de delegar en el arzobispo, descubriría asimismo, cómo Arturo es consciente del lugar que ocupa en el mundo y respecto al Creador, obediente y respetuoso a su ley. La susodicha alusión, por eso, funcionaría como una muestra de la disposición de Arturo a obedecer los mandamientos de Dios y constituiría una garantía de la sabiduría que habría de presidir un reinado largo y estable, sancionado por la divinidad ${ }^{44}$. Además, en esas primeras decisiones que adoptaba Arturo afloraba ya una de esas virtudes ligadas a la sabiduría innata, la prudencia. Ésta se consideraba la virtud que guiaba una conducta adecuada, basada en las buenas decisiones. Alonso de Cartagena la describía como hábito obrante con razón çerca los bienes e los males del onbre ${ }^{45}$, en tanto que Díaz de Games la caracterizó como discreçión de bien e de mal, deshechando el mal e usando el bien... distinçión del bien e del mal, con escogimiento del uno e deshechamiento del otro ${ }^{46}$, y Diego de Valera ${ }^{47}$, inspirado en San Agustín, como ciencia de las cosas que devemos desear e de las que devemos fuir o aborrescer. Afectaba, por tanto, a la parte activa del intelecto, a veces considerada inferior a la sabiduría o intelecto especulativo, en una relación mutua que se creía

${ }^{41}$ Baladro 1498, cap. XVII, p. 65. La versión de Sevilla repite literalmente el pasaje (Baladro 1535 , cap. CXXXIII, p. 50).

42 Ibidem; "de esto queremos saber vuestra voluntad sin consejo de otro" (Baladro 1535, cap. CXXXIV, p. 50).

${ }_{43}^{43}$ Nogales 2009-2010, pp. 318-319; Rice Jr. 1958, pp. 13-19.

${ }^{44}$ Nogales 2009-2010, p. 316.

${ }^{45}$ Campos 2004, p. 211.

${ }^{46}$ Gutierre Díaz de Games, El Victorial, ed. Rafael Beltrán 1997, p. 212.

${ }^{47}$ Diego de Valera, Doctrinal de príncipes, cap. VIII, en Penna, 1959-1964, vol. I, p. 191. 
análoga a la que existía entre el cuerpo y el alma. Sin embargo, ese saber lo que al ánima conviene faser al que el propio Valera se refería, invocando esta vez a Cicerón ${ }^{48}$, resultaba no sólo útil, sino imprescindible a la hora de ejercer el poder regio y, por tanto, para alcanzar el bien común del reino ${ }^{49}$. Las pruebas iniciales a las que los nobles de Logres someten a Arturo funcionan, pues, como tanteos con los que intentan reconocer en el joven las marcas de su cuna aristocrática, bajo la forma de rasgos morales. Y, aunque buena parte de las concepciones que respaldan este comportamiento se insertaban en una tradición doctrinal que remontaba a los Padres de la Iglesia, así como a los autores clásicos y a su recepción medieval, su vigencia perduraba durante la segunda mitad del siglo XV. Pero por otra parte, la actitud cauta hasta el extremo de los aristócratas bretones y su recurso a dichas concepciones éticas como prueba de toque del candidato al trono, se mostraban coherentes, una vez más, con las prevenciones sociales propias del Cuatrocientos y con la importancia que, en el terreno político, desempeñaban los modelos de monarca perfecto. Para la época aludida, el referente positivo de los Reyes Católicos ganaba en realce ejemplarizante cuando se contraponía con el antimodelo encarnado por Enrique IV; siendo así que la dialéctica entre aquéllos y éste último haría más oportunos retratos regios como los que proponía el Baladro.

La citada labor de caracterización moral del joven Arturo, de todas formas, no se detiene en esa escena previa a la coronación. Debido a las reservas que el nuevo soberano suscitaba entre los grandes del reino, a las primeras acciones de gobierno se les otorga el mismo valor probatorio. Y entre éstas sobresale, por las implicaciones que conlleva para el proceso de reescritura de los Baladros castellanos, la que lleva a cabo justo después de ceñirse la corona. Se trata del reparto de bienes del tesoro real entre sus nuevos vasallos, consejeros y ricohombres de la corte, que en el incunable de Burgos se efectúa de la siguiente manera:

e como falló a cada uno, así fizo él después: ca a los buenos dioles aves; e a los enamorados, las dueñas; e a los letrados, los averes; e a los de sus tierras dio lo que entendía que sería mejor. E así partió lo que le dieron por provarlo ${ }^{50}$.

${ }^{48}$ Ibidem.

${ }^{49}$ Kleine 2007,pp. 236-238; Nogales 2009-2010,pp. 323-324. Téngase en cuenta que, como recuerda Scandellari 2007, p. 154, una de las virtudes morales exigibles al monarca afectaba al arte del buen gobierno; y este consistía en la elección de aquellos medios necesarios para la consecución del bien común. Esta capacidad de realizar buenas elecciones en el transcurso de la acción gubernativa dependía precisamente de la prudencia, en tanto que virtud práctica. Tal es lo que demuestra Arturo en el pasaje que analizamos.

${ }^{50}$ Baladro 1498, cap. XVIII, p. 66. 


\section{La edición de 1535 presenta ligeras variantes:}

e como hallo assi hizo, ca a los buenos caualleros dio los cauallos e las armas, a los mancebos dio las aues, e a los enamorados dio las dueñas, e a los sesudos dio los aueres; e tuuolos en su conpañía, e a los de su tierra dio lo que entendio que les seria mejor; e assi partio lo que le dieron para prouarlo ${ }^{51}$.

Sin embargo, estos repartos resultan más significativos aún, cuando se confrontan con la distribución que describe el Merlin francés:

Quant il avoit pris lor avoirs, ses departoit si com li livres nos retrait: il donoit as bons chevaliers les chevaus, et as jolis et as envoisiez qui estoient amoros donoit ses joiaus, et as avers donoit deniers et or et argent, et as prodomes saiges et larges et bons vivandiers tenoit compoignie et a cels faisoit enquerre de l'un par l'autre quel chose li plaisoit miauz et il le lor donnoit. Einsi departi les dons que cil li donnoient qui essaioient de quel maniere il vouloit estre ${ }^{52}$.

Ya Micha ${ }^{53}$ llamaba la atención acerca de este pasaje de Robert de Boron, en el que veía reflejado el espíritu cortés del roman artúrico, lieu privilegié où regnent l'harmonie, la joie, la beauté. En él la largesse regia se ejercía, no tanto bajo la perspectiva de la sociedad feudal, favoreciendo a estamentos reconocibles, sino desde un punto de vista moral, más atento a las actitudes de diversos grupos humanos. De ahí, por ejemplo, la alusión a los enamorados o los avaros. En los Baladros, la alusión a la distribución de dones y sus respectivos beneficiarios profundizaría en ese tono cortés, de manera que se puede relacionar con el renacer de la cortesía que contempla el siglo XV, esa nueva edad trovadoresca, de la que habla Boase ${ }^{54}$ y cuyo fruto, como recuerda Beltran ${ }^{55}$, es el resurgimiento de la lírica amorosa a lo largo de esa centuria.

Sin embargo, la edición burgalesa añade algún otro pormenor que escapa a ese clima cortés y que apunta a otras realidades contemporáneas. Mientras que Boron explicaba que Arturo retuvo en su compañía a los hombres buenos, prudentes, generosos y hospitalarios y que a los avaros dio

${ }^{51}$ Baladro 1535, cap. CXXXV, pp. 50-51.

${ }^{52}$ Merlin, cap. 90, p. 287. La edición de Micha registra en este pasaje variantes en los mss. C (ms. 951 de la Biblioteca Municipal de Tours), D (ms. Additional 7071 de la Biblioteca Universitaria de Cambridge), G (ms. Reg. 1517 de la Biblioteca Vaticana), A' (ms. 24394 de la Biblioteca Nacional de Francia) y B' (ms. 526 de la Biblioteca Universitaria de Bonn), que, sin embargo, no resultan significativas para el objeto de este estudio.

${ }^{53}$ Micha 1980, p. 134.

${ }^{54}$ Boase 1981, pp. 96-97; Fernández 2002.

${ }^{55}$ Beltran 2002, pp. 24-25. 
dinero, oro y plata, en el texto sevillano el rey da bienes a los sesudos y los retiene consigo. En la edición de Burgos, en cambio, Arturo entrega esos bienes a los letrados. Sería erróneo interpretar esta mención como un simple desvío respecto al original francés, puesto que la alusión al grupo social de los letrados está cargada de intenciones y emite un juicio sobre la sociedad de la segunda mitad del XV. No en vano, el refundidor anónimo se estaría haciendo eco en este trance del auge que ese grupo social había experimentado a lo largo de la Baja Edad Media. Hasta tal punto sería así, que los sesudos, que menciona la edición sevillana, los hombres de saber y buen juicio, han sido desplazados en el texto de 1498 por este otro grupo, pasando pues de una actitud moral a un oficio que se caracterizaba no ya por sus conocimientos, sino por la aplicación de estos últimos a una tarea crucial en la organización política contemporánea. De ahí su poder y las suspicacias con que a veces podían ser mirados.

Los letrados ${ }^{56}$, como grupo social integrado por hombres del saber, formados en las universidades y expertos en tareas políticas, administrativas y jurídicas, emergen en la primera mitad del siglo XIV aupados por las nuevas necesidades que la recepción del Derecho Romano planteaba en las cancillerías regias, pero también por su utilidad en las labores de propaganda y legitimación monárquicas ${ }^{57}$. Esto último los convirtió en imprescindibles para las aspiraciones de expansión del poder regio. En la cancillería castellana irrumpen durante el reinado de Alfonso XI, desplazando a los clérigos en los oficios de corte ${ }^{58}$, y desde entonces afianzan su posición a lo largo de ese siglo y el siguiente. Enrique II les abre el acceso al Consejo Real, cuyo control consiguen, entre 1459 y 1465 , durante el reinado de Enrique IV $^{59}$ y, ya de manera más continuada, en el último cuarto del siglo XV. Los Reyes Católicos, por ejemplo, acogen en el Consejo Real a ocho o nueve letrados, frente a sólo tres caballeros, aunque también reservaban puestos honoríficos para miembros de los linajes nobiliarios ${ }^{60}$. En esos años, a medida que se institucionalizan los aparatos administrativos de los futuros estados modernos, los letrados se promocionan aprovechando la creciente especialización que requieren los nuevos órganos de gobierno, especialmente con la subida al trono de los Reyes Católicos y su apuesta por la profesionalización de dichos cargos gubernativos ${ }^{61}$. Con todo, esta ocupación de puestos de responsabilidad no supuso el despla-

${ }^{56}$ El surgimiento de este grupo profesional, con conciencia de unidad en el seno de la sociedad hispana medieval, ha sido estudiado por Maravall 1953.

${ }^{57}$ Nieto 2006, p. 135.

${ }^{58}$ Sanz 1990, pp. 190-193; Moxó 1975, pp. 5-30.

${ }^{59}$ Cabrera 1995, vol. I, p. 271.

${ }^{60}$ Fernández 2002,p. 64.

${ }^{61}$ Rucquoi 1995, p. 238. Esta apuesta por la profesionalización de los cargos administrativos se prolonga, no obstante, todo a lo largo de la Baja Edad Media (Torres 1982, pp. 24-25). 
zamiento de la nobleza de su lugar preeminente en la Corte. Cuánto más que los propios nobles, ante el reforzamiento del nuevo grupo social, optaron por aprovechar ellos mismos los mecanismos de promoción que ofrecía la formación intelectual, de manera que se hizo letrada una parte de sus integrantes, a la vez que también procuraban cegar las vías de ascenso social de esos recién $\operatorname{llegados}^{62}$. El proceso de fusión de ambos grupos sociales fue más allá, ya que el desempeño de cargos académicos y político-administrativos se convirtió en una posible vía de acceso a la nobleza y dio lugar a la formación de una auténtica aristocracia de toga, que aspiró a mimetizarse con la vieja nobleza de linaje $^{63}$. Pero la promoción social de los letrados no se limitó a la adquisición de los privilegios nobiliarios y a la formación de señoríos. Más llamativa, si cabe, resultó la acumulación de bienes, fruto de las mercedes que les otorgaban los sucesivos monarcas por sus servicios. Precisamente fue su cercanía a los reyes, como sucedía con el cargo de los secretarios regios, la que garantizó que medrasen sus fortunas de manera cuantiosa y a menudo rápida ${ }^{64}$. No pasaron desapercibidos estos súbitos aumentos de patrimonio, según denuncia Gonzalo Fernández de Oviedo en sus Batallas y quinquagenas al referirse al comendador don Pedro de Quintana, secretario y miembro del Consejo de Fernando el Católico. En ellas refiere, con un cierto tono de censura, que Gran copia de secretarios aragoneses es la que habemos visto en tiempo del Rey Cathólico, y todos medrados y ricos en poco tiempo, y mejorados en nobleza de sus personas e en renta e patrimonios ${ }^{65}$.

No resultaría, por tanto, casual que el refundidor del Baladro burgalés fijase los averes como las mercedes más apreciadas que Arturo podía conceder a los letrados. Y más si se tiene en cuenta que el escándalo que ocasionaba el crecimiento de sus riquezas fue acompañado en ocasiones por el que producían los métodos ilícitos usados en su consecución. No en vano, el propio Fernández de Oviedo se refiere en otro pasaje de las Batallas y quinquagenas a las tres vías que en su tiempo existían en Castilla para reunir grandes haciendas y rentas. Uno lo constituían los cargos eclesiásticos y los otros dos, los letrados legos y los de la péñola, ambos ocupados de los oficios administrativos de la monarquía. Pues bien, de estos últimos destaca su venalidad y sus ansias de enriquecimiento, aun a costa del delito, cosa que

${ }^{62}$ Cabrera 1995, p. 271; Perez 1982, pp. 448-449.

${ }^{63}$ Sanz 1990, p. 190. La formación de esta nueva aristocracia no pasó desapercibida, como muestra el testimonio de Hernando del Pulgar: "Vemos por experiencia algunos hombres destos que juzgamos nascidos de baxa sangre forzarles su natural inclinacion á dexar los oficios baxos de los padres, é aprender sciencias, é ser grandes letrados" (Letras de Fernando de Pulgar, Letra XIV, p. 158).

${ }^{64}$ Fernández 2002, p. 72.

${ }^{65}$ Pérez de Tudela 1983-2002, t. II, batalla I, quinquagena III, diálogo X, t. II, p. 215. 
conseguían del siguiente modo: a los de la péñola con hacerlos contadores mayores, tesoreros e secretarios e otros oficios con que desplumen a otros e se enriquezcan a sí mismo ${ }^{66}$. Resulta significativo, por tanto, no sólo que el reelaborador burgalés considerase a los letrados como parte imprescindible de la corte artúrica, hasta el punto de hacerles un hueco entre los beneficiarios de los favores regios, sino que éstos apreciasen, por encima de otras mercedes, las riquezas que habían de favorecer su ascenso social.

Como sucede con este pasaje, los anteriores que se han analizado en las páginas precedentes apuntan hacia una reconsideración de ciertos aspectos contenidos en las antiguas versiones de la historia de Merlín, la cual fue acompañada de las pertinentes modificaciones textuales. No por puntuales, dichos cambios carecen de importancia, pues, como hemos podido observar, afectan a conceptos claves, aducidos en la obra, que conllevan una reintrepretación de la misma. Los casos que hemos estudiado a lo largo del presente trabajo muestran, a este respecto, cómo la lectura de los Baladros, a finales del siglo XV y comienzos del XVI, se hacía eco de las preocupaciones en torno a la crisis de la aristocracia caballeresca, a la amenaza a que la sometía la aparición de nuevas instancias de poder, como los letrados, al surgimiento de una nobleza advenediza, formada por villanos enriquecidos, y, en fin, todo ello presidido por el reforzamiento de la autoridad monárquica. La capacidad de adaptación de los relatos artúricos, a lo largo del siglo XVI, debería entenderse a la luz de estos mecanismos de reescritura, bien que su destino, marcado por la competencia de las emergentes novelas de caballerías, demostraría las limitaciones de tal proceder.

\section{BIBLIOGRAFÍA CITADA}

Alfonso X, Las siete partidas del rey don Alfonso el Sabio, cotejadas con varios códices por la Real Academia de la Historia, 3 vols., Madrid, Imprenta Real, 1807

Baranda, Nieves (ed.) (1995), Corónica del Çid Ruy Díaz, en Historias caballerescas del siglo XVI, Madrid, Biblioteca Castro - Turner, vol. I, pp. 1-109.

Bäuml, Franz H. (1980), Varieties and Consequences of Medieval Literacy and Illiteracy, "Speculum" 55/2, pp. 237-265.

Beltran, Vicenç (2002), Edad Media: lírica y cancioneros, Barcelona, Crítica.

${ }^{66}$ Ibidem, batalla I, quinquagena II, diálogo IV, pp. 188-189. 
Bizzarri, Hugo (1995), Las colecciones sapienciales castellanas en el proceso de reafirmación del poder monárquico (siglos XIII y XIV), "Cahiers de Linguistique Hispanique Médiévale" 20, pp. 35-73.

Boase, Roger (1981), El Resurgimiento de los trovadores. Un estudio del cambio social y el tradicionalismo en el final de la Edad Media en Espa$\tilde{n} a$, Madrid, Pegaso.

Bonilla San Martín, Adolfo (ed.) (1907), El Baladro del sabio Merlín, en Libros de caballerías. Primera parte: ciclo artúrico, ciclo carolingio, Madrid, Bailly-Baillière, pp. 3-162.

Cabrera, Emilio (1995), Los grupos privilegiados en Castilla en la segunda mitad del siglo XV, en Ribot García, Luis Antonio; Carrasco Martínez, Adolfo; Fonseca, Luís Adão da (coords.), Congreso Internacional de Historia El Tratado de Tordesillas y su época. Setúbal, 2 de junio, Salamanca 3, 4 de junio, Tordesillas 5, 6, 7 de junio de 1994, Valladolid, Sociedad V Centenario del Tratado de Tordesillas, vol. I, p. 265-290.

Cacho Blecua, Juan Manuel (1999), El género del "Cifar" (Sevilla, Cromberger, 1512), "Thesaurus" 54/1, pp. 76-105.

Campos Souto, Mar (ed.) (2004), Alonso de Cartagena. El Memorial de virtudes: la traducción castellana del Memoriale virtutum de Alonso de Cartagena, Burgos, Ayuntamiento de Burgos.

Fernández de Córdova Miralles, Álvaro (2002), La Corte de Isabel I. Ritos y ceremonias de una reina (1474-1504), Madrid, Dykinson.

García Vera, María José (1993), Poder nobiliario y poder político en la Corte de Enrique IV (1454-1474), "En la España Medieval” 16, pp. 223-238.

Gerbet, Marie-Claude (1972), Les guerres et l'accès à la noblesse en Espagne de 1465 à 1592, "Mélanges de la Casa de Velázquez" 8, pp. 295-326.

González Crespo, Esther (2008), Pecados de los monarcas en la Baja Edad Media, en Carrasco Manchado, Ana Isabel; Rábade Obradó, María del Pilar (coords.), Pecar en la Edad Media, Madrid, Sílex, pp. 27-54.

González-Vázquez, Sara (ed.) (2013), Représentation et théorisation de la noblesse dans les traités castillans $d u X V^{e}$ siècle: une édition du Nobiliario Vero de Ferrán Mexía, Lyon, École Normale Supérieure (tesis doctoral) URL: https://tel.archives-ouvertes.fr/tel-00951093 [consulta: 31/10/2015].

Gracia, Paloma (2007), Los Merlines castellanos a la luz de su modelo subyacente: la Estoria de Merlín del ms. 1877 de la Biblioteca Universitaria de Salamanca, en Cacho Blecua, Juan Manuel (coord.), De la literatura caballeresca al Quijote, Zaragoza, Universidad de Zaragoza, pp. 233-248. 
Gracia, Paloma (2012), Avatares ibéricos del ciclo de la Post-Vulgate: el título del Baladro del sabio Merlín con sus profecías (Burgos, 1498) y la colección profética derivada de la Historia Regum Britanniae, "Zeitschrift für Romanische Philologie" 128/3, pp. 507-521.

Green Jr., James Ray (1980), La forma de la ficción caballeresca del siglo XVI, en Gordon, Alan M.; Rugg, Evelyn (coord.), Actas del Sexto Congreso Internacional de Hispanistas celebrado en Toronto del 22 al 26 de agosto de 1977, Toronto, University of Toronto, pp. 353-355.

Gutierre Díaz de Games, El Victorial, estudio, edición crítica, anotación y glosario de Rafael Beltrán Llavador Salamanca, Ediciones Universidad de Salamanca, 1997.

Haro Cortés, Marta (1996), La imagen del poder real a través de los compendios de castigos castellanos del siglo XIII, Londres, Queen Mary and Westfield College.

Hernández, María Isabel (ed.) (1999), El Baladro del sabio Merlín con sus profecías, vol. II, Gijón, Trea.

Heusch, Carlos (1996), El Renacimiento del aristotelismo dentro del humanismo español, “Atalaya. Revue Française d'Études Médiévales Hispaniques" 7, pp. 11-40.

Heusch, Carlos (2000), La caballería castellana en la baja Edad Media, Montpellier, Université de Montpellier III.

Infantes, Víctor (1989), La prosa de ficción renacentista: entre los géneros literarios y el género editorial, "Journal of Hispanic Philology" 13, pp. 115-124.

Jauss, Hans Robert (1976), La literatura como provocación, Barcelona, Península.

Jauss, Hans Robert (1978), Pour une esthétique de la réception, París, Gallimard.

Kleine, Marina (2007), La virtud de la prudencia y la sabiduría regia en el pensamiento político de Alfonso X el Sabio, "Res Publica. Revista de Historia de las Ideas Políticas" 17, pp. 223-239.

Leroy, Béatrice (2011), Le Doctrinal des Princes de Diego de Valera, en Fournès, Ghislaine; Canonica, Elvezio (eds.), Miroir du prince. Écriture, transmission et réception en Espagne (XIII ${ }^{e}-X V I^{e}$ siècles), Burdeos, Presses Universitaires de Bordeaux, pp. 225-238.

Letras de Fernando de Pulgar (1775), en Centon epistolario del bachiller Fernán Gómez de Cibdareal. Generaciones y Semblanzas del noble caballero Fernán Pérez de Guzmán. Claros Varones de Castilla, y Letras de Fernando de Pulgar, Madrid, Imprenta Real de la Gazeta.

Lucía Megías, José Manuel (2013), Los códices corrientes caballerescos: hacia un nuevo modelo librario, en Martínez Pérez, Antonia; Alvar, 
Carlos; Flores, Francisco J. (coord.), Uno de los buenos del reino. Homenaje al Prof. Fernando Carmona, San Millán de la Cogolla, Cilengua - Fundación San Millán de la Cogolla, pp. 361-389.

Lucía Megías, José Manuel (2015), The Surviving Peninsular Arthurian Witnesses: A Description and an Analysis, en Hook, David (ed.), The Arthur of the Iberians. The Arthurian Legends in the Spanish and Portuguese Worlds, Cardiff, University of Wales Press, pp. 33-57,

Maravall, José Antonio (1953), La formación de la conciencia estamental de los letrados, "Revistas de Estudios Políticos" 70, pp. 53-81.

Martin, Georges (2008), Le concept de "naturalité" (naturaleza) dans les Sept parties, d'Alphonse X le Sage, "e-Spania. Revue Interdisciplinaire d'Études Hispaniques Médiévales et Modernes" 5, URL: http:// e-spania.revues.org/10753 [consulta: 30/05/2015]

Mártir Rizo, Juan Pablo (2008), Historia de la muy noble y leal ciudad de Cuenca, Mairena del Aljarafe, Extramuros Edición (ed. facsímil de Madrid, 1629).

Micha, Alexandre (ed.) (1979), Robert de Boron. Merlin, roman du XIII ${ }^{e}$ siècle, Ginebra, Droz.

Micha, Alexandre (1980), Étude sur le "Merlin" de Robert de Boron, Roman $d u$ XIII" siècle, Ginebra, Droz.

Middleton, Roger (2006), The Manuscripts, en Burgess, Glynn S.; Pratt, Karen (eds.), The Arthur of the French. The Arthurian Legend in Medieval French and Occitan Literature, Cardiff, University of Wales Press, pp. 9-92.

Montanari, Massimo (1993), El hambre y la abundancia. Historia y cultura de la alimentación en Europa, Barcelona, Crítica.

Moxó, Salvador de (1975), La promoción política y social de los "letrados" en la corte de Alfonso XI, "Hispania. Revista Española de Historia" 35/129, pp. 5-30.

Nieto Soria, José Manuel (1988), Fundamentos ideológicos del poder real en Castilla (siglos XIII-XVI), Madrid, EUDEMA.

Nieto Soria, José Manuel (2006), Ideología y representación del poder regio en la Castilla de fines del siglo XV, "Estudios de Historia de España" 8, pp. 133-162.

Nieto Soria, José Manuel (2008), La Segunda Partida en los debates políticos de la Castilla del siglo XV, "e-Spania. Revue Interdisciplinaire d'Études Hispaniques Médiévales et Modernes" 5, URL: http:// e-spania.revues.org/9993 [consulta: 30/05/2015]

Nogales Rincón, David (2009-2010), En torno a la sabiduría en el Cuatrocientos castellano: el prólogo a la traducción castellana del De regno ad 
regem Cypri de Tomas de Aquino dirigida a Fernando el Católico, "Memorabilia. Boletín de Literatura Sapiencial" 12, pp. 289-350.

Pagden, Anthony Robin Dermer, (1975), The Diffusion of Aristotle's moral philosophy in Spain, "Traditio" 31, pp. 287-313.

Penna, Mario (1959-1964), Prosistas castellanos del siglo XV, 2 vols., Madrid, Ediciones Atlas.

Perez, Joseph, (1982), Los letrados, "Bulletin Hispanique" 84/3-4, pp. 443-453.

Pérez de Tudela y Bueso, Juan (ed.) (1983-2002), Gonzalo Fernández de Oviedo. Batallas y quinquagenas, 4 vols., Madrid, Real Academia de la Historia.

Quintanilla Raso, María Concepción (2008), “Nobilitas virtutis causa””. De la virtud al pecado en la nobleza, en Carrasco, Ana Isabel; Rábade Olmedo, María del Pilar (coords.), Pecar en la Edad Media, Madrid, Sílex, pp. 151-158.

Rice Jr., Eugene F. (1958), The Medieval Idea of Wisdom, en Rice Jr., Eugene F., The Renaissance Idea of Wisdom, Westport (Connecticut), Greenwood Press, pp. 1-29.

Rodríguez, Ana (2003), De rebus Hispaniae frente a la Crónica latina de los reyes de Castilla: virtudes regias y reciprocidad política en Castilla y León en la primera mitad del siglo XIII, "Cahiers de Linguistique et de Civilisation Hispanique Médiévales" 26, pp. 133-149.

Rodríguez Velasco, Jesús (1996), El debate sobre la caballería en el siglo XV. La tratadística caballeresca castellana en su marco europeo, Valladolid, Junta de Castilla y León.

Rucquoi, Adeline (1995), Democratie ou monarchie. Le discours politique dans l'université castillane au XV siècle, en Guglielmi, Nilda; Rucquoi, Adeline (eds.), El discurso político en la Edad Media, Buenos Aires, Consejo Nacional de Investigaciones Científicas y Técnicas, pp. 233-255.

Russell, Peter E.; Pagden, Anthony R. D. (1974), Nueva luz sobre una versión española cuatrocentista de la Ética a Nicómaco, Bodleian Library MS Pan.d. I., en Homenaje a Guillermo Guastavino, Madrid, Asociación Nacional de Bibliotecarios, Archiveros y Arqueólogos, pp. 125-146.

Sanz Fuentes, María Josefa (1990), Cancillería y cultura en la Castilla de los siglos XIV y XV, en Gualdo, Germano (ed.), Cancelleria e cultura nel Medio Evo. Comunicazioni presentate nelle Giornate di Studio della Commisione Stoccarda, 29-30 agosto 1985. XVI Congresso Internazionale di Scienze Storiche, Ciudad del Vaticano, Archivio Segreto Vaticano, pp. 187-199. 
Scandellari, Simonetta (2007), Mosén Diego de Valera y los consejos a los príncipes, "Res Publica" 18, pp. 141-162.

Soriano Robles, Lourdes (2013), La literatura artúrica de la península Ibérica: entre membra disiecta, unica y códices repertoriales, "e-Spania. Revue Interdisciplinaire d'Études Hispaniques Médiévales et Modernes" 16. DOI: 10.4000/e-spania.22792.

Torres Sanz, David (1982), La administración central castellana en la Baja Edad Media, Valladolid, Universidad de Valladolid.

Trujillo, José Manuel (2011), Los nietos de Arturo y los hijos de Amadís. El género editorial caballeresco en la Edad de Oro, "Edad de Oro" 30, pp. 415-441.

Fecha de recepción del artículo: diciembre 2015

Fecha de aceptación y versión final: octubre 2016 